\title{
THE TECHNO-ECONOMIC POTENTIAL OF OFFSHORE WIND ENERGY WITH OPTIMIZED FUTURE TURBINE DESIGNS IN EUROPE
}

\section{Dilara Gulcin Caglayan, ${ }^{1}$ David Severin Ryberg ${ }^{1}$, Heidi Heinrichs ${ }^{1}$, Jochen Linßen ${ }^{1}$, Detlef Stolten $^{1,2}$, Martin Robinius ${ }^{1}$}

1 Institute of Energy and Climate Research - Electrochemical Process Engineering (IEK-3) Forschungszentrum Juelich GmbH, 52425 Juelich, Germany

2 RWTH Aachen University, c/o Institute of Energy and Climate Research - Electrochemical Process Engineering (IEK-3) Forschungszentrum Juelich GmbH, 52425 Juelich, Germany d.caglayan@fz-juelich.de, s.ryberg@fz-juelich.de, h.heinrichs@ fz-juelich.de, j.linssen@fzjuelich.de, $\underline{\text { m.robinius@fz-juelich.de, } \text { d.stolten@fz-juelich.de }}$

\begin{abstract}
Renewable energy sources will play a central role in the sustainable energy systems of the future. Scenario analyses of such hypothesized energy systems require sound knowledge of the technoeconomic potential of renewable energy technologies. Although there have been various studies concerning the potential of offshore wind energy, higher spatial resolution, as well as the future design concepts of offshore wind turbines, has not yet been addressed in sufficient detail. Here, we aim to overcome this gap by applying a high spatial resolution to the three main aspects of offshore wind potential analysis, namely ocean suitability, the simulation of wind turbines and cost estimation. A set of constraints is determined that reveal the available areas for turbine placement across Europe's maritime boundaries. Then, turbine designs specific to each location are selected by identifying turbines with the cheapest levelized cost of electricity (LCOE), restricted to capacities, hub heights and rotor diameters of between 3-20 MW, 80-200 m and 80-280 m, respectively. Ocean eligibility and turbine design are then combined to distribute turbines across the available areas. Finally, LCOE trends are calculated from the individual turbine costs, as well as the corresponding capacity factor obtained by hourly simulation with wind speeds from 1980 to 2017. The results of cost-optimal turbine design reveal that the overall potential for offshore wind energy across Europe will constitute nearly 8.6 TW and 40.0 PWh at roughly $7 €_{\mathrm{ct}} \mathrm{kWh}^{-1}$ average LCOE by 2050. Averaged design parameters at national level are provided in an appendix.
\end{abstract}

Keywords: Offshore wind energy, future turbine design, floating foundation, fixed-bottom foundation, levelized cost of electricity.

\section{INTRODUCTION}

With the European Union's (EU) target of greenhouse gas emission reduction by $80 \%$ to $95 \%$ of the level in 1990 until 2050, the role of renewable energy sources in the energy systems of the future has become significant. Of these, variable renewable energy sources (VRES) like onshore and offshore wind energy, as well as open-field and roof-top photovoltaics (PV), will increase their 
share in the energy mix of many countries. At the end of 2017, the total installed capacity of renewables around the world was nearly $2.2 \mathrm{TW}$, representing an $8.3 \%$ increase in capacity against 2016 [1]. Only $5 \mathrm{GW}$ of this increase was comprised of new offshore wind installations, of which $4 \mathrm{GW}$ were installed by European countries [1]. Many studies foresee the continuing growth of offshore wind capacity in the future. For example, the EU released a reference scenario by projecting current trends into the future, from which a total installed offshore wind capacity of 45 GW in 2050 was derived [2]. By comparison, in the forecast developed within the E-Highway study's [3] "100\% RES" scenario, $115 \mathrm{GW}$ of offshore wind capacity is expected by 2050 . For both studies, only fixed-bottom turbines in the North Sea are taken into account; however, due to recent technological developments in floating foundations, it is becoming more apparent that offshore wind can also play a role outside of the North Sea [4]. In light of this, Green Peace created their "Energy [R] evolution" forecast, in which a total of $148 \mathrm{GW}$ of offshore wind capacity is expected across Europe through 2050 [5]. These exemplary scenarios show that the exact extent of future offshore wind expansion remains uncertain.

Several analyses have determined offshore wind potential on different scales, ranging from the global to regional levels. These methods can mostly be applied to any spatial scale and different VRES, such as onshore wind or PV, with some changes in data and assumptions. Most often, the methods to determine the offshore wind potential consist of eligibility assessments, derivation of total potential capacity by a power density factor and the calculation of Full Load Hours (FLH) as an indication of location quality. In order to discuss the methods, currently available studies to determine offshore wind potential will be described, as well as data and assumptions employed in each analysis, as differences in the latter aspects cause significant variation in the results, despite their similar methods and scopes. Table 1 illustrates the capacity and generation results for the European Union and Norway available in the literature. Europe as a whole is considered by all the studies except WindEurope [6], in which only the North Sea, Baltic Sea and Atlantic from France to the north of the UK are considered. The studies will be compared with regard to an eligibility assessment, determination of capacity and the calculation of full load hours.

Table 1. Potential analyses for offshore wind energy available in the literature.

\begin{tabular}{lccc}
\hline Source & Context & $\begin{array}{c}\text { European } \\
\text { capacity (TW) }\end{array}$ & $\begin{array}{c}\text { European } \\
\text { generation } \\
\text { (TWh) }\end{array}$ \\
\hline EEA [7] & Europe & 0.82 & 3,400 \\
Arent et al. [8] & Global & 10.49 & n.a. \\
WindEurope ${ }^{1}$ [6] & Partly Europe & 3.0 & 13,000 \\
Bosch et al. [9] & Global & 26.9 & 115,000 \\
Zappa and van den Broek [10] & Europe & 5.9 & n.a. \\
\hline
\end{tabular}

${ }^{1}$ Only the North Sea, Baltic Sea and Atlantic Ocean from France to the Northern UK are considered in the analysis. 
In terms of the eligibility assessment, all the studies performed an analysis to determine the total available area, yet assumptions such as the constraints and corresponding values differ. EEA [7] and Zappa and van den Broek [10] performed the eligibility analysis by using suitability factors that accounted for unavailable areas. Only areas of water up to $50 \mathrm{~m}$ in depth were investigated by the EEA, whereas the threshold was $1000 \mathrm{~m}$ for Zappa and van den Broek [10] due to their inclusion of floating wind turbines. In addition to the water depth constraint, protected areas are excluded by others. A maximum shore distance is employed by Arent et al. [8] and Bosch et al. [9] as $185 \mathrm{~km}$ and $370 \mathrm{~km}$, respectively; whereas this constraint is not employed by Wind Europe [6]. Subsea cables are excluded by Bosch et al. [9], as well as Wind Europe [6], by which sea ice, thresholds of wind speeds and shipping lanes are additionally excluded. Following the eligibility assessment, calculation of the total available capacity is required. In all of the aforementioned analyses, the potential was calculated by using a power density constant to indicate installable capacity per unit area. The value of this constant differs with respect to the separation distance between turbines, as well as the turbine characteristics, mainly consisting of capacity and rotor diameter. The potential values in the European Environment Agency (EEA) [7] and Wind Europe [6] are determined in accordance with the characteristics of one future turbine design, whereas Arent et al. [8], Bosch et al. [9] and Zappa and van den Broek [10] considered contemporary turbine definitions with capacities ranging between 1.5 MW and $8 \mathrm{MW}$. A turbine with capacity, rotor diameter and hub height values of $10 \mathrm{MW}, 150 \mathrm{~m}$ and $120 \mathrm{~m}$ was used by EEA [7]. The capacity, rotor diameter and hub height of the turbine used by Wind Europe in their baseline scenario are $13 \mathrm{MW}, 212 \mathrm{~m}$ and $128 \mathrm{~m}$, respective, whereas they are $15 \mathrm{MW}, 228 \mathrm{~m}$ and $136 \mathrm{~m}$ in the upside scenario. Alongside the differences in the turbine characteristics, the corresponding power density factors in each study vary between 5 and $6 \mathrm{MW} \mathrm{km-2,} \mathrm{except} \mathrm{in} \mathrm{EEA} \mathrm{[7],} \mathrm{by} \mathrm{which}$ this factor is assumed to be $15 \mathrm{MW} \mathrm{km}^{-2}$.

In addition to variations in the estimation of total capacity, FLHs are calculated by employing different methods and weather data. For the EEA [7], FLHs are calculated by an empirical equation depending on the average wind speed at the location, originating from climate model data by Arent et al. [8], who used a Weibull distribution with a represented power curve-determining FLH. The National Centers for Environmental Prediction (NCEP) Climate Forecast System Reanalysis and Reforecast Wind Hind Cast dataset is used for wind offshore simulations by Wind Europe [6]; however, the applied simulation method is opaque due to gaps in documentation. Hourly wind speeds obtained from the Modern-Era Retrospective analysis for Research and Applications 2 (MERRA-2) dataset extracted across a 35-year timeframe are averaged into a single time series and segmented into 32 consecutive bins by Bosch et al. [9]. Afterwards, these wind speeds are applied to a wind simulation method developed by Staffel et al. [11], which is validated against historical grid-fed wind generation data. This method applies a power curve convolution to improve the generation estimations, as well as country-specific wind speed bias-correction factors. Finally, the capacity factors are multiplied by a power density factor to estimate the available capacity within a region. Zappa and van den Broek [10] made use of a 3-hourly resolved weather dataset to provide wind speeds, which is temporally coarser than MERRA-2. When simulating, 
power curve convolution, similar to the approach of Staffel et al. [11], is employed, in addition to a $13 \%$ holistic loss.

Despite many investigations of offshore wind energy potential on different scales, there are still important points in need of being addressed or improved. Primarily, this includes the need for higher spatial and temporal resolution, as well as consideration of future turbine designs. Coarse temporal resolution, for example on a 3-hourly [10] basis, as well as annual aggregation [9], affect the accuracy of the results due to the intermittency of wind energy and the non-linear response of wind turbines. The spatial resolution is also important in identifying prime locations. Up until now, the results of offshore wind potentials are mostly presented at a national level with overall available capacity and total generation potential. Nevertheless, identifying potential regions at a national scale is vital, especially for further use in energy system design, which for the time-being is often performed on an aggregated spatial scale [12-14]. However, the trend towards more detailed energy system analyses and increasingly detailed sectoral analyses, such as electrical grid expansion planning, requires highly resolved spatial and temporal offshore wind potentials that have not been available up until now [15]. In addition to the temporal and spatial resolutions, it is necessary to take different turbines into account in order to efficiently utilize the energy of a region. For example, the use of a wind turbine suitable for higher wind speeds on large scales, such as in the European region or worldwide, may cause underestimation of the potential of regions with lower wind speeds. Therefore, similar to Bosch et al. [9], different classes of wind speeds and corresponding turbine designs should be taken into account. The method used in some studies ([610]) to calculate the generation potential of offshore wind turbines and their actual placement enhances a potential analysis by incorporating the geographical context of the region, unlike the use of power density factors alone. Finally, taking into account future projections and estimates regarding turbine designs, increases in rotor diameter and capacity are evident [16]. Although taking contemporary turbine designs into account is necessary in near-future decision-making processes, analyses concerning long-term future energy systems and consideration of future turbine designs are crucial. In particular, the latter is still missing from in literature and bears the biggest uncertainties due to its predictive nature.

All in all, a transparent and reproducible method for determining the potential of offshore wind is essential and required by future analyses, so that the results can be periodically updated with advancements in technologies and allowing for a critical discussion of methods, assumptions and data [17]. In the present study, an offshore wind potential analysis in the context of 2050 is performed within European maritime boundaries with consideration of future turbine designs. The overall methodology consists of the best qualities of the aforementioned approaches, such as the consideration of realistic constraints within the eligibility assessment and hourly wind energy simulations. Moreover, overall electricity generation is estimated by explicitly placing and simulating individual wind turbines instead of using a constant power density factor. Two scenarios are investigated: one in which a single turbine design is installed across Europe and another where different turbine designs are considered in order to tailor designs in response to 
location-specific wind conditions and other site characteristics. This cost-optimal turbine design scenario requires the evaluation of nearly 6,000 turbine designs with different hub heights, capacities, rotor diameters and foundations for each location in order to determine the design with the lowest levelized cost of electricity (LCOE). Hence, this study enhances some fundamental aspects of the analysis of offshore wind potential and aims to support decision making in the realm of integrating renewable energy technologies into our energy systems.

In the following, this paper describes the method utilized in Section 2, including the assumptions made for the analyzed scenarios. In Section 3, the obtained results for each stage of the analysis are presented and discussed. This comprises ocean eligibility, turbine design in terms of capacity, hub height, foundation type, rotor diameter and FLHs for the second scenario, and finally LCOEs for both the single and cost-optimal turbine design scenarios. Finally, the paper concludes with general findings and some suggestions for further research. 


\section{METHODOLOGY}

When determining the offshore wind energy potential of any given region, three issues can be addressed more or less independently of each other: determining suitable areas for turbine placement, performance evaluation of turbines in response to wind speeds and, finally, cost estimation. Methodological approaches for addressing these three independent, fundamental aspects are developed in this work and then combined to evaluate scenarios of single-turbine and cost-optimal turbine design across Europe. As a result of this analysis, the total available capacity, electricity generation and associated costs for European countries are investigated. Figure 1 illustrates the overall workflow employed herein. As is shown in Figure 1, the three fundamental aspects used in the analysis are independent of each other. Therefore, the orders in the figure and text vary in order to maintain a cohesive narrative.

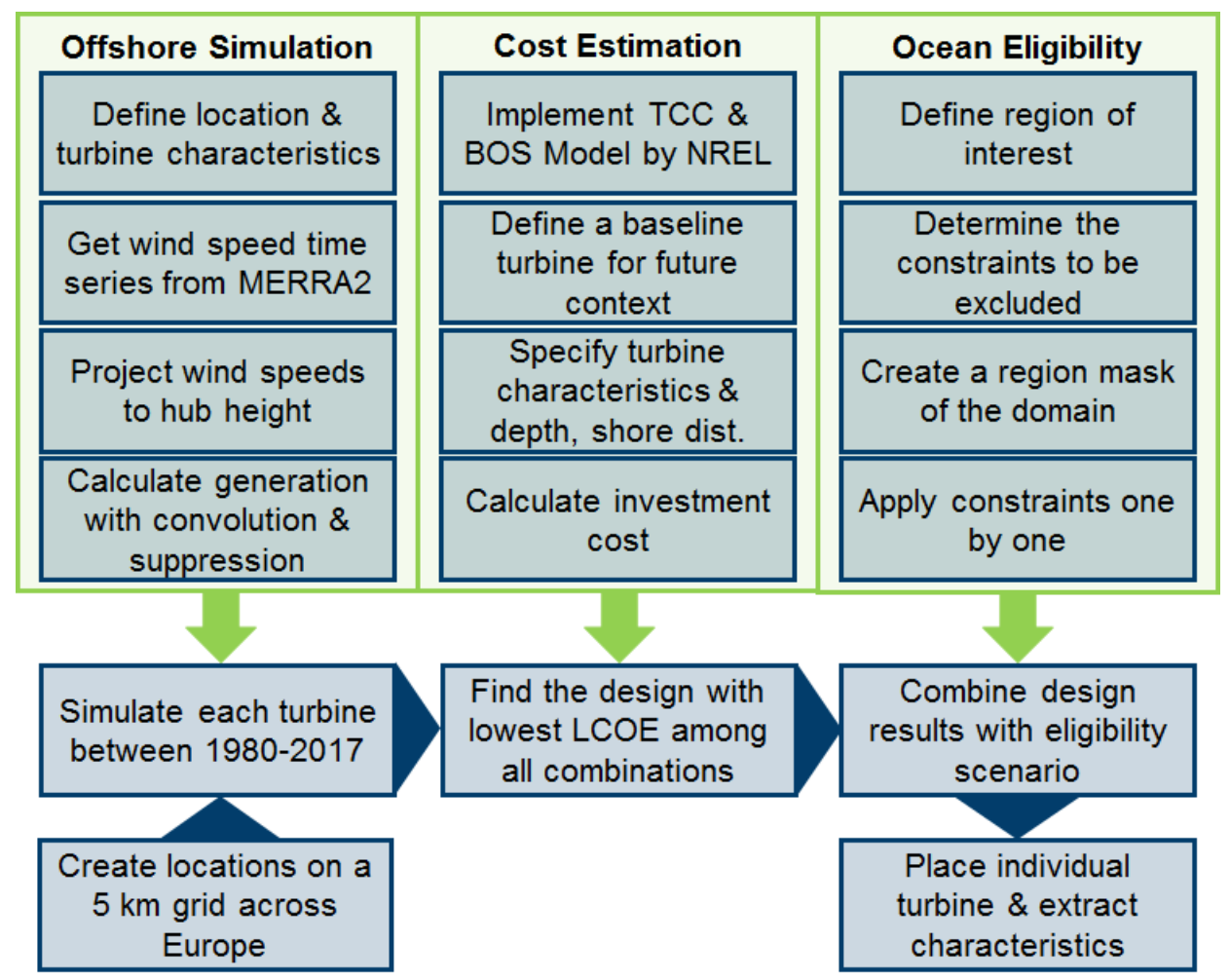

Figure 1. Representation of the methodology and procedure applied for the analysis.

\subsection{Ocean eligibility}

In order to determine the amount of ocean area available, an ocean eligibility analysis is performed using the open-source model, Geospatial Land Availability for Energy Systems (GLAES), developed by Ryberg et al. [18], based on Robinius et al. [19,20]. The GLAES tool was specifically designed to perform area eligibility analyses in a reproducible and transparent manner. When given a regional definition and spatial resolution, the GLAES model can apply exclusion constraints from any geospatial datasets according to the user's needs. After the exclusion procedure, GLAES 
is capable of distributing items within the eligible space subject to a minimal direction-dependent separation distance between any two items.

In this work, the entire offshore region around Europe is processed at a resolution of $100 \mathrm{~m} \mathrm{x}$ $100 \mathrm{~m}$. Then, the constraints described in Table 2 are applied in succession, resulting in the exclusion of all ineligible offshore areas. These exclusions are determined on the basis of a review of previous analyses that have investigated ocean eligibility in various contexts (cf. [6-10,21,22]).

Table 2. Constraints used in the ocean eligibility analysis.

\begin{tabular}{llll}
\hline Constraint & \multicolumn{2}{c}{ Excludes } & Data Source \\
\hline Water Depth & above & $1000 \mathrm{~m}$ & {$[23]$} \\
Distance to Shore & below & $15000 \mathrm{~m}$ & {$[24]$} \\
Protected Areas & below & $3000 \mathrm{~m}$ & {$[25]$} \\
Birds Protected Areas & below & $5000 \mathrm{~m}$ & {$[25]$} \\
Shipping Routes & below & $3000 \mathrm{~m}$ & {$[26]$} \\
Pipelines & below & $500 \mathrm{~m}$ & {$[27]$} \\
Cable Lines & below & $500 \mathrm{~m}$ & {$[28,29]$} \\
\hline
\end{tabular}

Water depth: The latter stages of this work will consider both fixed-bottom and floating foundation designs. Therefore, offshore areas with a maximum water depth of $1000 \mathrm{~m}$ are allowed, as they correspond to the maximum depth at which floating wind turbines can be installed [30]. Additionally, in the turbine design phase of this work, specific water depth restrictions for the various foundation options are taken into account. Bathymetric raster data from General Bathymetric Chart of the Oceans from the British Oceanographic Data Center [23], at a resolution of $0.0083^{\circ}$ (roughly $800 \mathrm{~m}$ ) is used to identify these areas due to its high spatial resolution.

Distance to Shore: Shore distance is mainly considered to reduce visual and audible disruptions caused by wind turbines. From a physical standpoint, due to the curvature of the Earth wind turbines should not be visible beyond $45 \mathrm{~km}$ [7]. Nevertheless and in comparison to the other constraints, shore distance is strongly dependent on the preferences of the local stakeholders and can vary greatly from region to region. For example, in 2009 it was stated that the Netherlands forbids the construction of wind farms within $22 \mathrm{~km}$ of the shore [7]. In the context of shore visibility, Hong and Möller [21] suggest a value of between 8 and $19 \mathrm{~km}$, while Jay [22] settles on $19 \mathrm{~km}$. Hill et al. [31] investigated visibility in detail as a function of terrain elevation on the Scottish shore and found that a distance of $15 \mathrm{~km}$ is sufficient, assuming that a viewer is at a height of $6 \mathrm{~m}$ above sea level. In order to give a uniform treatment across the European context, it is decided to exclude all areas within $15 \mathrm{~km}$, which is directly calculated from the Euclidian distance from country boundaries defined by the Database of Global Administrative Areas [24].

Protected Areas: Protected areas are generally excluded in order to preserve their ecological and historical heritage. For this, the World Database of Protected Areas (WDPA) [25] is used, which 
includes such areas for most countries in the world. Following the approach of Hong and Möller [21], a buffer distance of $3 \mathrm{~km}$ is applied for all designated areas. Furthermore, areas corresponding to protected bird habitats are buffered by an additional $2 \mathrm{~km}$ [21]. In reality, not all protected areas preclude the construction of offshore wind parks, as seen clearly by the example of Dogger Bank, a nearly $5 \mathrm{GW}$ farm in the North Sea that is situated in one of the largest protected areas excluded by this constraint. Nevertheless, in order to avoid subjective preprocessing of the WDPA dataset, no filtering is applied.

Shipping Routes: To ensure that the placement of turbines does not prohibit ship transportation, common shipping routes should be excluded as well. Jay [22], for example, excluded all shipping routes with a buffer of $3.6 \mathrm{~km}$. Similarly, Hong and Möller [21] distinguished between low, medium and high traffic routes and excluded them with buffers of 1, 3, and $3.7 \mathrm{~km}$, respectively. Since explicit designations of traffic density are not made in the data sources used here, a buffer distance of $3 \mathrm{~km}$ is utilized for all shipping routes. The definition of these routes originates from a raster source containing the relative likelihood of a ship passing through each pixel [26]. Common routes were traced manually, but as the precise width of these routes is not known, a constant width of $4 \mathrm{~km}$ was assumed. Furthermore, all pixels with a value above 17000 (relative units) were used to define the areas associated with the most heavily used routes, around which the $3 \mathrm{~km}$ buffer is applied.

Infrastructure: Submerged pipelines and cables must be avoided in order to not disrupt their operation; therefore, in accordance with the suggestion of Hong and Möller [21], a buffer distance of $500 \mathrm{~m}$ is excluded around all features. For this purpose, vector sources for natural gas pipeline routes [27] and cables [28,29] are used.

Aside from the exclusion constraints mentioned above, other constraints appear in the literature as well, including fishing areas, oil and gas platforms and military reserved areas. In all cases, these considerations were not included here due to lack of consistent European data. In spite of this, the major offshore eligibility considerations are included, and as such the addition of the missing constraints are not expected to have a large influence on the resulting available area.

\subsection{Wind turbine performance evaluation}

Instead of developing a novel turbine simulation scheme, the workflow of Ryberg et al. [32] is used and adapted to the offshore context. This workflow was developed for the simulation of onshore wind turbines and was shown to be valid when simulating groups of turbines for both contemporary and future turbine designs. The use of global climate model data, wind speed adjustment to a local context, synthetic power curve estimation and futuristic turbine designs are the key components of the workflow. As the method is previously described in detail [32], the changes made for the current use case are discussed further.

While both workflows make use of the MERRA-2 global climate model dataset, the spatial adjustment of extracted wind speeds is handled differently. In this case, bilinear interpolation is 
used to estimate wind speeds for specific latitude and longitude coordinates. Similarly, a logarithmic wind speed profile is assumed in both onshore and offshore workflows. However, since all locations evaluated here are over open water, a constant roughness length of $0.0002 \mathrm{~m}$ is used [33,34]. Despite the simplification in the roughness length due to the lack of data, the impact on the results can be negligible [33]. Four constants are used by Ryberg et al. [32] in order to better capture wind energy dynamics compared to the use of a holistic loss factor. By simulating existing offshore wind parks in Germany, updated values for each of these constants for the offshore wind workflow are found. For the two convolution constants, scaling and base factors of 0.04 and 0.5 , respectively, are used. For the low generation correction constants, base and sharpness factors of 0.1 and 3.5 were chosen.

\subsection{Cost model}

Periodically, the National Renewable Energy Laboratory (NREL) releases cost breakdowns of onshore and offshore turbines in the United States, in which turbine costs are categorized into three groups: turbine capital cost (TCC), balance of system cost (BOS) and financial cost (FIN) [35]. In order to take into account the variation of these costs with respect to turbine design, as well as location-specific parameters such as water depth and foundation, cost models developed by NREL to calculate TCC $([36,37])$ and offshore BOS [38] are used, as they are the most up-to-date models available and take these parameters into account. The TCC model was developed in 2006, updated in 2010, and bases its cost estimations on total turbine mass. Ultimately, the TCC model is a nonlinear function of three fundamental characteristics, namely: turbine capacity, hub height and rotor diameter. Meanwhile, the offshore BOS model was developed in 2017 and, in addition to capacity, hub height and rotor diameter, is also primarily dependent on distance to shore, water depth and foundation type. Two fixed-bottom foundational options are considered, monopile and jacket, as well as two floating options, spar and semisubmersible. As both of these models were designed according to turbine costs at the time of their inception, they are not directly applicable to future applications such as in 2050, and therefore adjustment is required. For this purpose, the final cost model (see Eqs. 1-3) is the scale cost estimations made by NREL's TCC, BOS and FIN models to baseline assumptions of future turbine costs and designs while maintaining their sensitivities to changes in turbine and location characteristics:

$$
\begin{aligned}
T C C^{\prime} & =\frac{\operatorname{cost}_{b} * \theta_{T C C} * T C C(c, h, r)}{T C C\left(c_{b}, h_{b}, r_{b}\right)} \\
B O S^{\prime} & =\frac{\operatorname{cost}_{b} * \theta_{B O S} * B O S(c, h, r, d, s, f)}{B O S\left(c_{b}, h_{b}, r_{b}, d_{b}, s_{b}, f_{b}\right)}
\end{aligned}
$$

where $\theta_{T C C}$ and $\theta_{B O S}$ stand for the shares of TCC and BOS for the selected baseline turbine, $c, h$, $r, d, s$ and $f$ represent capacity, hub height, rotor diameter, water depth, shore distance and foundation type of the turbine, and cost is the final cost estimation. Likewise, subscript $b$ indicates the assumed values of the baseline turbine. Finally $T C C^{\prime}$ and $B O S^{\prime}$ represent the corresponding 
TCC and BOS of the evaluated turbine. In line with the latest cost breakdown from NREL, $\theta_{T C C}$ and $\theta_{B O S}$ are always assumed as 0.329 and 0.462 for fixed-bottom foundations versus 0.236 and 0.608 for floating foundations [35].

In this way, when given a baseline assumption of turbine design and cost that represents the typical turbine design in the envisioned timeframe, the resulting cost model can be used to estimate variations of turbine cost when designs deviate. For example, when introducing the BOS model, Maness et al. [38] selects a baseline turbine characterized by a capacity of $6 \mathrm{MW}$, with a rotor diameter of $154 \mathrm{~m}$, hub height of $90 \mathrm{~m}$, shore distance of $40 \mathrm{~km}$ and water depth of $25 \mathrm{~m}$ with a monopile foundation for their sensitivity analysis. For the later turbine design stage of the costoptimal scenario, these characteristics will be used as the initial baseline turbine, which does not necessarily reflect the typical design to be determined by the optimization.

In order to be able to compare different turbine designs, simply knowing the total cost is insufficient. The design of a turbine can influence total energy generation, and therefore the levelized cost of electricity (LCOE) is used for comparison. This is calculated in the manner described by Ryberg et al. [32] with the following assumptions: an economic lifetime of 25 years [39], a specific operating cost of $2 \%$ and an interest rate of $8 \%$ [39].

\subsection{Scenario analyses}

\subsubsection{Turbine design}

The performance and cost of the turbines are of course a function of the design of the turbines. In the first scenario, constant values for capacity, hub height and rotor diameter can be assumed for all offshore locations. In comparison, a more detailed analysis could suggest unique turbine designs for all locations based on objectives such as the minimization of the LCOE. Both approaches are taken in this analysis. A single turbine design scenario is used in order to better compare the results with the literature, while cost-optimal designs are used for the final evaluation.

For the single turbine analysis, a turbine with a capacity of $13 \mathrm{MW}$ and $212 \mathrm{~m}$ rotor diameter and $128 \mathrm{~m}$ hub height is employed, as it reflects a future turbine design that is well within the range predicted by industry experts [40]. However, in order to determine cost-minimal designs in the main scenario of this analysis, the full design boundaries suggested by Wiser et al.[40] are explored. As a result, the capacity is allowed to vary between 3-20 MW, with a hub height of 80$200 \mathrm{~m}$ and a rotor diameter between 80-280 m. Additionally, in order to ensure more realistic turbine designs, a minimal blade-tip to sea-level distance of $30 \mathrm{~m}$ is assumed and designs which violate this are disqualified. Due to computational limitations, the characteristics are discretized, resulting in increments of $0.2 \mathrm{MW}$ in turbine capacity, $2 \mathrm{~m}$ for hub height, and $5 \mathrm{~W} \mathrm{~m}^{-2}$ in specific power. Furthermore, foundation options are limited according to water depth. Fixed monopile and jacket foundations are only permitted between depths of 0 and $100 \mathrm{~m}$, while floating semisubmersible foundations are allowed between 20 and $1000 \mathrm{~m}$ and floating spar of between 100 and $1000 \mathrm{~m}$ [38]. 
In order to determine the most cost-effective overall design, all locations on a $5 \mathrm{~km}$ grid across Europe's offshore areas are considered. At this stage, ocean eligibility is not factored in so that the results can be combined with different exclusion scenarios in the future. For each location, all the possible turbine designs within the upper and lower boundaries are simulated, as described in Section 2.2 between 1980 and 2017 to obtain the corresponding average capacity factor. Afterwards, the corresponding LCOE is calculated for each turbine design and the turbine specifications with the minimum LCOE are chosen.

\subsubsection{Turbine placement}

The resulting turbine designs are combined with the previously computed ocean eligibility results in order to identify designs within the eligible regions. This is done for both the single turbine design scenario, as well as the cost-minimal turbine design scenario. In each case, the item distribution feature of the GLAES model is employed to distribute the maximum number of potential turbines with a minimal separation distance defined by 10 by 4 times the rotor diameter [41], oriented in the predominant wind speed direction at each location. As the rotor diameters at each location are different between scenarios, the resulting number and distribution of potential locations will not be the same. For each identified potential placement of the cost-minimal turbine design scenario, turbine characteristics are extracted from the design results.

\subsubsection{Selection of baseline turbine for the final economic analysis}

Performing the final economic analysis in the cost-minimal turbine design scenario requires the definition of a new baseline turbine that reflects future cost estimations as well as the result of the design analysis. With regard to turbine cost, there are several estimations in the context of 2050 $[39,42,43]$. Taking the average of these values in the literature provides a value of $2300 € \mathrm{~kW}^{-1}$ as a baseline cost, which is approximately the same value as that used in the reference scenario by the Joint Research Center (JRC) [42]. In order to determine the design characteristics corresponding to this cost value, monopile foundations are assumed to be the most common which, by only selecting the placements with a monopile foundation, leads to the baseline turbine characteristics from the observed averages, namely: 9.4 MW capacity, $135 \mathrm{~m}$ hub height and $210 \mathrm{~m}$ rotor diameter. 


\section{RESULTS \& DISCUSSION}

\subsection{Ocean eligibility}

In the evaluation of ocean eligibility, a uniform application of the constraints is applied across Europe. Figure 2 presents the resulting viable areas, shown in green and obtained by applying the constraint set described in Section 2.1. Across Europe, 1,648,000 $\mathrm{km}^{2}$ are found to be available, which constitutes $31.5 \%$ of the total area. Similar analysis performed by Arent et al. [8] reported an eligible area of 2,000,000 $\mathrm{km}^{2}$ for the same region definition. The difference in the results of these two studies can be explained by different assumptions, such as not considering shipping lanes, having $9.2 \mathrm{~km}$ distance from shore for visual impact and excluding only protected areas without buffer. In addition, the available and total area as well as the percentage share of the available area at a national level can be found in the appendix. It should be noted that these results may vary by changing the scenario of this analysis, as the output is directly dependent on the assumed distances and constraints. For instance, the use of an additional constraint or an increase in the buffer distances could decrease the eligible areas within the region. It is obvious that the key constraint in the determination of eligible land is the water's depth. This effect can be seen by comparing the North Sea and Mediterranean Sea. While the North Sea provides a considerable amount of eligible areas, as much as $400 \mathrm{~km}$ from the shore, the same does not hold in the Mediterranean Sea. This is mainly a result of water depth, as the Mediterranean is fairly deep unlike the relatively shallow North Sea. This is especially pronounced off of western Italy, as well as eastern France and Spain. In general, most of the areas are eliminated in the Bay of Biscay, Mediterranean Sea and Portuguese regions in the Atlantic Ocean.

The significance of protected areas is accentuated around Corsica, northwestern Italy and southeastern France. In these regions, the protected area of the Pelagos Sanctuary for the Conservation of Marine Mammals excludes approximately $113,000 \mathrm{~km}^{2}$ - the largest of all protected areas within Europe's maritime boundaries. It is followed by northeast Faroe-Shetland Channel, Dogger Bank and Wadden Sea with areas of 43,600 km², 32,000 km² and 19,700 km², respectively.

Although shipping lanes do not occupy as much of an area as the area excluded by water depth constraint or protected areas, the impact of this constraint is discernible. This is especially evident in the convergence of routes within the English Channel. Similar behavior can be seen in the strait of Gibraltar, the North Sea and Baltic Sea.

In addition, the possible foundation types defined by water depth are visualized across the eligible areas shown in Figure 2. Northern Russia, southern Ukraine and a small portion of western Denmark are the few eligible areas where only fixed-bottom foundation types are available, with depths of less than $20 \mathrm{~m}$. Semisubmersible is found to be the most versatile foundation type. 


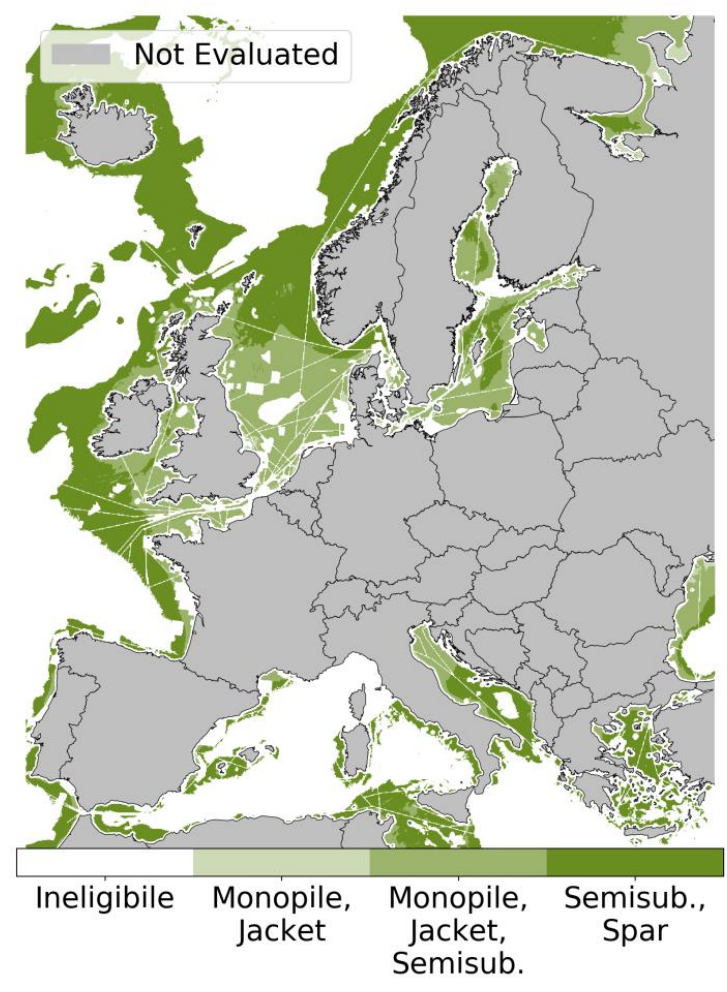

Figure 2. Ocean eligibility results with the different foundation types.

\subsection{Turbine design}

This section shows the specifications of cost-optimal turbine designs across Europe. Independent of the ocean eligibility assessment, the analysis remains general and applicable to other eligibility scenarios. However, the discussion of these results will mainly focus on the suitable locations within the constraint scenario outlined. As previously mentioned, the region of interest comprises European maritime boundaries excluding Iceland. Therefore, the areas belonging to northern African countries such as Morocco and Tunisia are not presented here.

Figure 3 displays the resulting turbine design characteristics, including capacity (a), hub height (b), foundation type (c) and the corresponding FLH (d). Focusing first on the capacity distribution reveals that a large variety of capacities result from cost optimality. Turbines with lower capacities are preferred in areas with low sea depth and low wind speed, which can often be found closer to shore. Although lower capacities are primarily installed in near shore areas, there are some exceptions such as near-to the Dogger Bank area in the North Sea, where relatively low capacities are found despite being far from shore. This observation supports the trend of lower capacity turbines installed in regions with relatively low wind speeds. This can be explained by the low cost sensitivity of the selected increments in capacity in that area. Where high wind speeds are found, the maximum capacity observed in this analysis occurs around the northern UK, Ireland and southern France. In general, the designed capacities in the deep sea regions are approximately $16 \mathrm{MW}$, whereas this value decreases to $10 \mathrm{MW}$ in the near-shore North Sea region with low sea depth. Average capacity values per country can be found in appendix. 
Like capacity distribution, there is some similarity in lower hub heights of between $130-140 \mathrm{~m}$ in the near-shore North Sea and northern Adriatic Sea, as is shown in Figure 3(b). Likewise, in deeper waters, and especially in the Mediterranean Sea and Bay of Biscay, hub heights are in the range of 160-170 m. The maximum hub height of $200 \mathrm{~m}$ can mainly be observed in the Mediterranean Sea, where a floating foundation is necessary. The vast majority of locations attaining a $200 \mathrm{~m}$ hub height are excluded due to water depth, however. In general, as distance from shore increases, hub height always increases with reference to the respective magnitude at the coast due to increasing water depth. The abrupt variation in the middle of the North Sea is one exception to this, however. This variation in hub height as well as capacity is mainly due to the hub height discretization, resulting in cascading design changes in the other parameters. A more in depth investigation reveals that despite this discrete design step, there is only a negligible change in the final LCOE of $0.02 \%$ with finer discrete design steps. Compared with a previous analysis of onshore wind energy, hub height design is seemingly the opposite of the onshore turbine design trend predicted by Ryberg et al. [32] where, as a rule, capacity increases and hub height decreases, along with increasing average wind speed. In this case, the rise in hub heights while moving away from the shore corresponds to increasing wind speed. This effect is caused by the BOS functions, where the cost is not as sensitive to hub height compared to the other parameters, such as distance to shore or water depth. Therefore, high hub heights in deep sea regions are preferred in order to access higher FLH and offset the increase in investment costs. High hub heights are not unique to the deep sea, however, as it can be seen that higher hub heights and lower capacities are chosen for locations near to shore and with lower wind speeds.

The distribution of foundation types is shown in Figure 3(c). In addition, the share of each foundation type per nation is also available in the appendix. The jacket is not chosen except in a few regions that are extremely close to shore, whereas in near-shore regions it is predominantly monopile. Spar in particular is chosen when close to shore and with water depths greater than $100 \mathrm{~m}$, as is seen in the areas surrounding Italy and much of Spain. Depending slightly on the distance to shore, there is a distinct transition between a monopile and semisubmersible foundation around $50 \mathrm{~m}$ in water depth. This is notable because it is within the range where all foundation options except spar are possible, and yet jacket is still not selected. In their report, Maness et al. [38] state that monopile is economically preferred between 0-40 m water depth, after which jacket should become the most economical option. Nevertheless, this is not observed here, which may be caused by the difference in U.S. versus European deployment.

Figure 3(d) shows the distribution of FLH in the region of interest ranging between 2000-6000 $\mathrm{h} \mathrm{a}^{-}$

1 . Despite the wide range observed across Europe, there is a clear difference between regions. For example, the values of FLH in the North Sea and Northwestern British Isles attain 5000-6000 $\mathrm{h} \mathrm{a}^{-}$

1. On the other hand, FLHs are generally below $4500 \mathrm{~h} / \mathrm{a}$ in the Adriatic Sea, with some even lower than $3500 \mathrm{~h} \mathrm{a}^{-1}$. Independent of the average FLH in a region, there is always an increase in the FLH as distance from the shore increases. In the very near shore cases, this can be caused by the chance arrangement of the MERRA-2 grid cells that are oriented directly over the coastline. Complex micro-scale climactic interactions caused by the terrain are not well reflected within the 
single MERRA-2 cell due to its low resolution, and because of this, inconsistent design behavior is possible. This is especially noticeable in western Portugal and southwestern France. In spite of this behavior, these areas are excluded due to the distance to shore constraint and do not affect the final results that are presented in this analysis. 


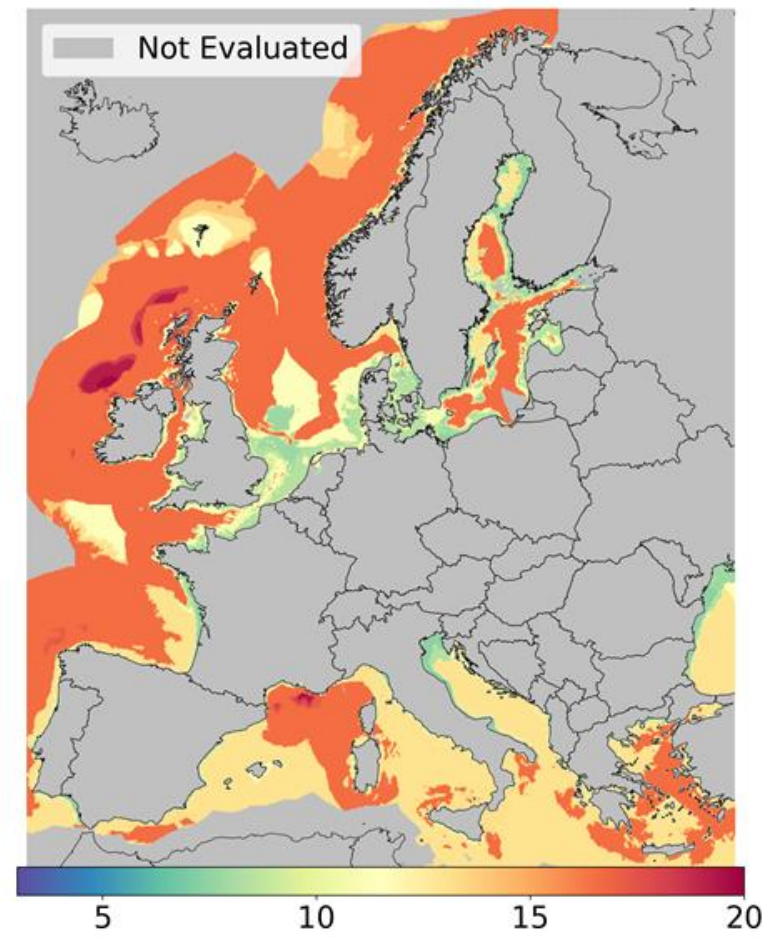

(a) Capacity [MW]

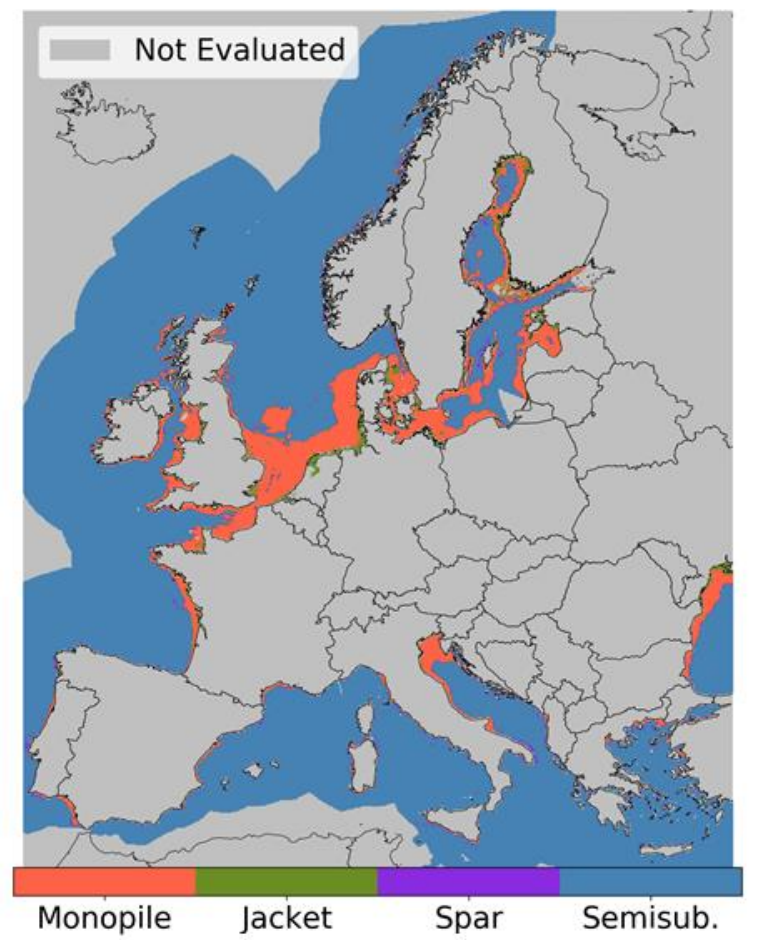

(c) Foundation

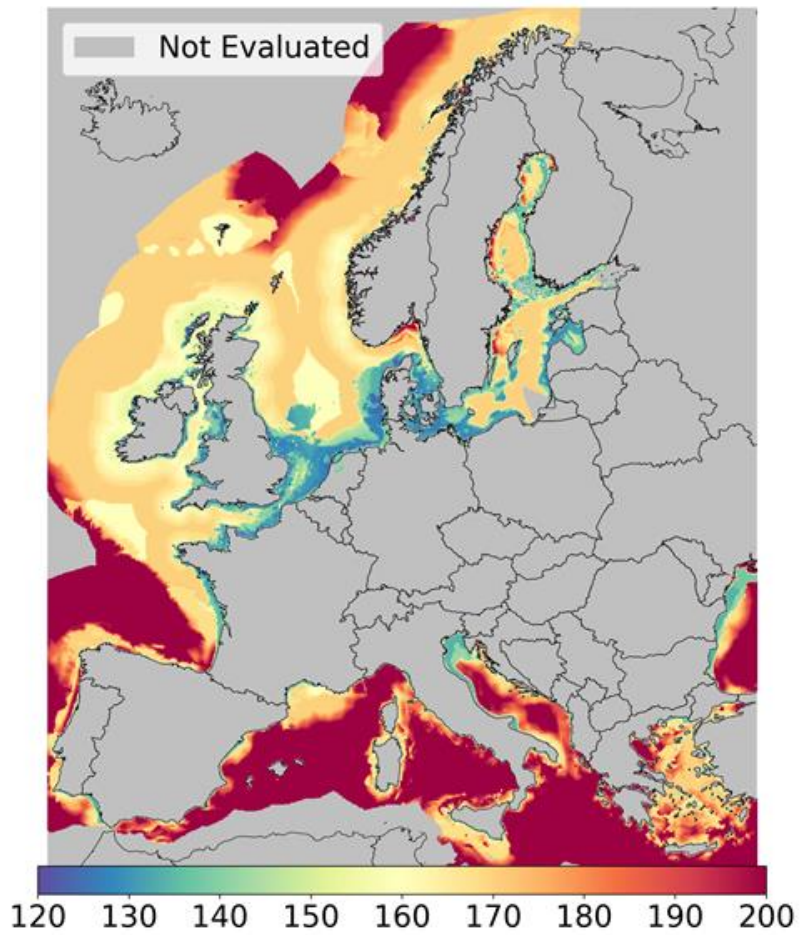

(b) Hub Height [m]

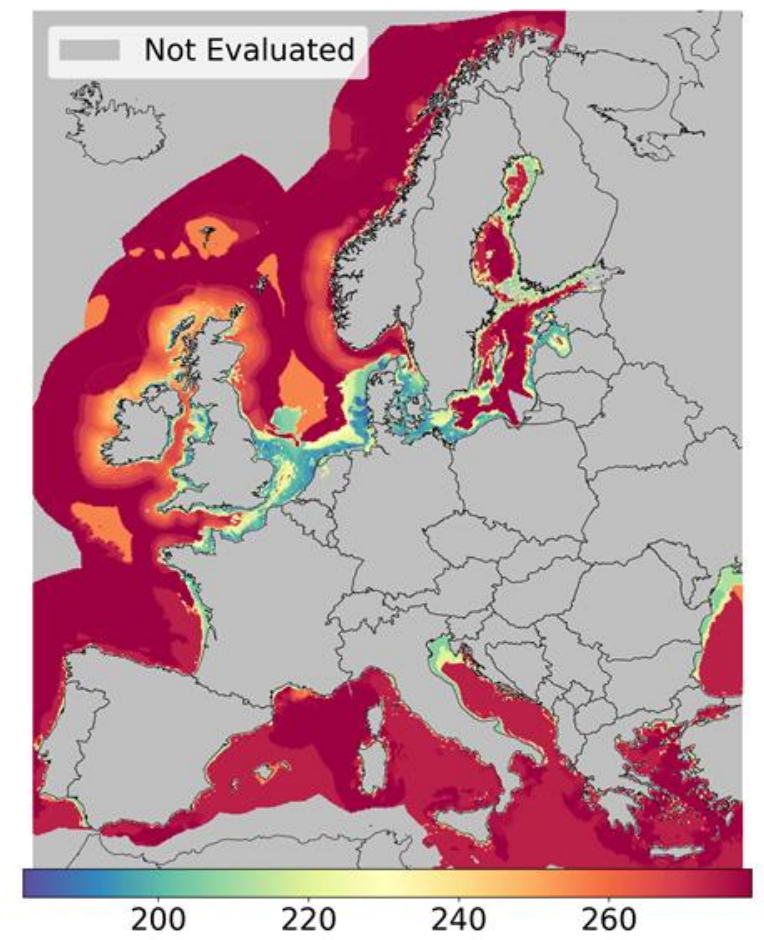

(d) Rotor Diameter [m]

Figure 3. Specifications of resulting turbine design across European maritime boundaries, a) capacity, (b) hub height, (c) foundation, (d) rotor diameter. 


\subsection{Evaluation of the techno-economic potential of offshore wind with a single turbine design}

As previously described, the turbine used in the single turbine design scenario has a capacity of $13 \mathrm{MW}$ with a $212 \mathrm{~m}$ rotor diameter and $128 \mathrm{~m}$ hub height, corresponding to the baseline scenario of Wind Europe [6]. The placement of this turbine is performed across all eligible areas, totaling 956,000 potential locations, each of which was simulated between 1980 and 2017 to calculate the average capacity factor for each location. The total capacity, generation and average FLH across all locations was $12.4 \mathrm{TW}, 43.65 \mathrm{PWh}$ and $3500 \mathrm{~h} \mathrm{a}^{-1}$, respectively. Afterwards, by using the constant turbine specifications in addition to depth and shore distance values specific to each location, the turbine cost is calculated. LCOE is then calculated on the basis of the cost, as well as the average FLH. Figure 4 compares LCOE estimates available in the literature to the distribution of results observed in this scenario and the optimal turbine design. Although the analysis is performed in the context year 2050, LCOE enhancements over time are shown so that the importance of future turbine designs can be clearly recognized.

A few studies have cost projections through 2050 and predict values of between $4-12 €_{\mathrm{ct}} \mathrm{kWh}^{-1}$ $([2,5,40,42,44])$; however, they are generally performed by using an average capacity factor and cost for the single turbine design across Europe. In addition to the projections in 2050, two reports published by Kost et al. [45] and Hobohm et al. [46] provide LCOE estimations for Germany through 2035 and 2023, respectively. Hernandez et al. [47] estimate LCOE for fixed-bottom wind turbines, only considering deep water and up to $50 \mathrm{~km}$ distance from shore for 2025 and 2030. European Wind Energy Association (EWEA) [48] reported a decrease in LCOE down to $9 €_{\mathrm{ct}} \mathrm{kWh}^{-}$ ${ }^{1}$ by 2030. Moreover, IRENA [16] published a cost estimation for offshore wind energy in 2020 in accordance with global trends and outlooks. When the method explained in Section 2 is employed, the results with a single turbine design show a wide range across Europe concerning the distribution to all eligible locations. Nevertheless, $75 \%$ of turbines with single turbine design are in the range of 4-12 $€_{\mathrm{ct}} \mathrm{kWh}^{-1}$, which shows good agreement with the LCOE values determined in the literature. Ultimately, in this scenario, the average LCOE of all turbines that can be placed within the eligible area is found to be $10.6 €_{\mathrm{ct}} \mathrm{kWh}^{-1}$, whereas the median is $9.2 €_{\mathrm{ct}} \mathrm{kWh}^{-1}$. 


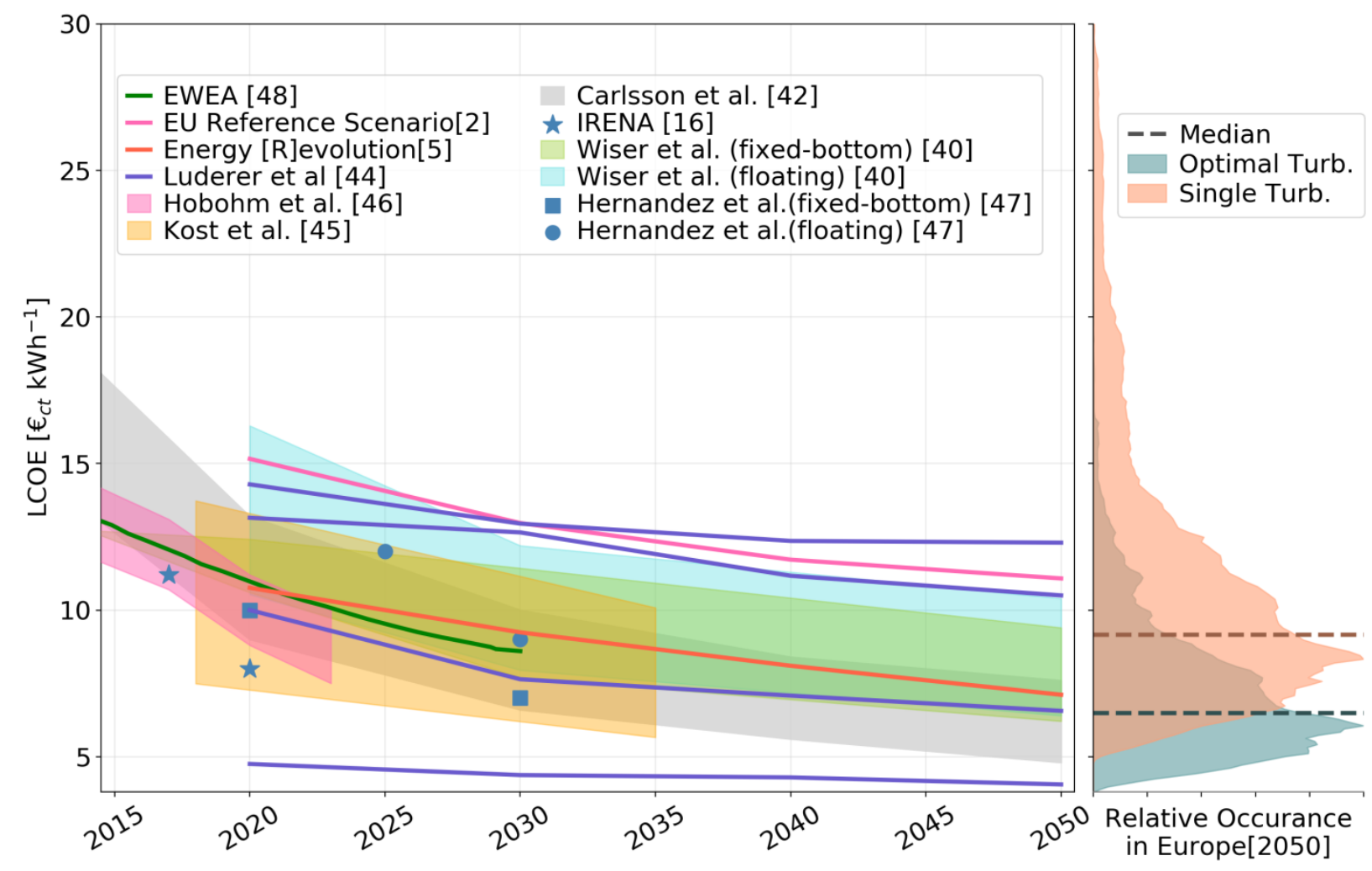

Figure 4. Comparison of LCOE calculated by this approach with the literature. Left: LCOE estimations in the literature changing by year, right: the relative occurrence of the LCOE for a single turbine design ${ }^{2}$ and optimal turbine design in the context of 2050.

\subsection{Evaluation of techno-economic wind offshore potential with multiple future turbine designs}

In order to perform the cost-optimal scenario analysis explained in Section 2.4.1, approximately 590,000 turbines are placed across the European region on suitable land. The capacity of these varies between 3.8-19.8 MW; interestingly, $20 \mathrm{MW}$ is not chosen anywhere, even though it was within the boundaries of the turbine's design. The total available capacity and generation potentials across Europe are found to be 8.6 TW and 39.86 PWh, with an average FLH of $4650 \mathrm{~h} \mathrm{a}^{-1}$. There is a significant difference in the outcomes of both scenarios, exemplified in Figure 5 from the overall LCOE distributions. This difference is more pronounced in the low wind speed regions, as low specific capacity turbines are used to increase the power output in the cost-optimal scenario. On average, using a location-specific turbine design results in better performance compared to the single turbine definition, as higher FLH is preferred in the cost-optimal design due to its effect on the LCOE. Therefore, low capacity wind turbines are chosen for low wind speed regions. Further investigation of the characteristics of the designed turbines leads to the typical turbine definition

${ }^{2}$ A single turbine has a capacity of $13 \mathrm{MW}$ with a $212 \mathrm{~m}$ rotor diameter and $128 \mathrm{~m}$ hub height [6]. 
of 9.4 MW, $135 \mathrm{~m}$ hub height and $210 \mathrm{~m}$ rotor diameter, as is mentioned in Section 2.4.3. Scaled according to this new baseline turbine definition, the specific investment of $95 \%$ of the placed turbines varies between $1500-4500 € \mathrm{~kW}^{-1}$, although a small percentage, especially in far from shore floating locations, can extend up to $8000 € \mathrm{~kW}^{-1}$.

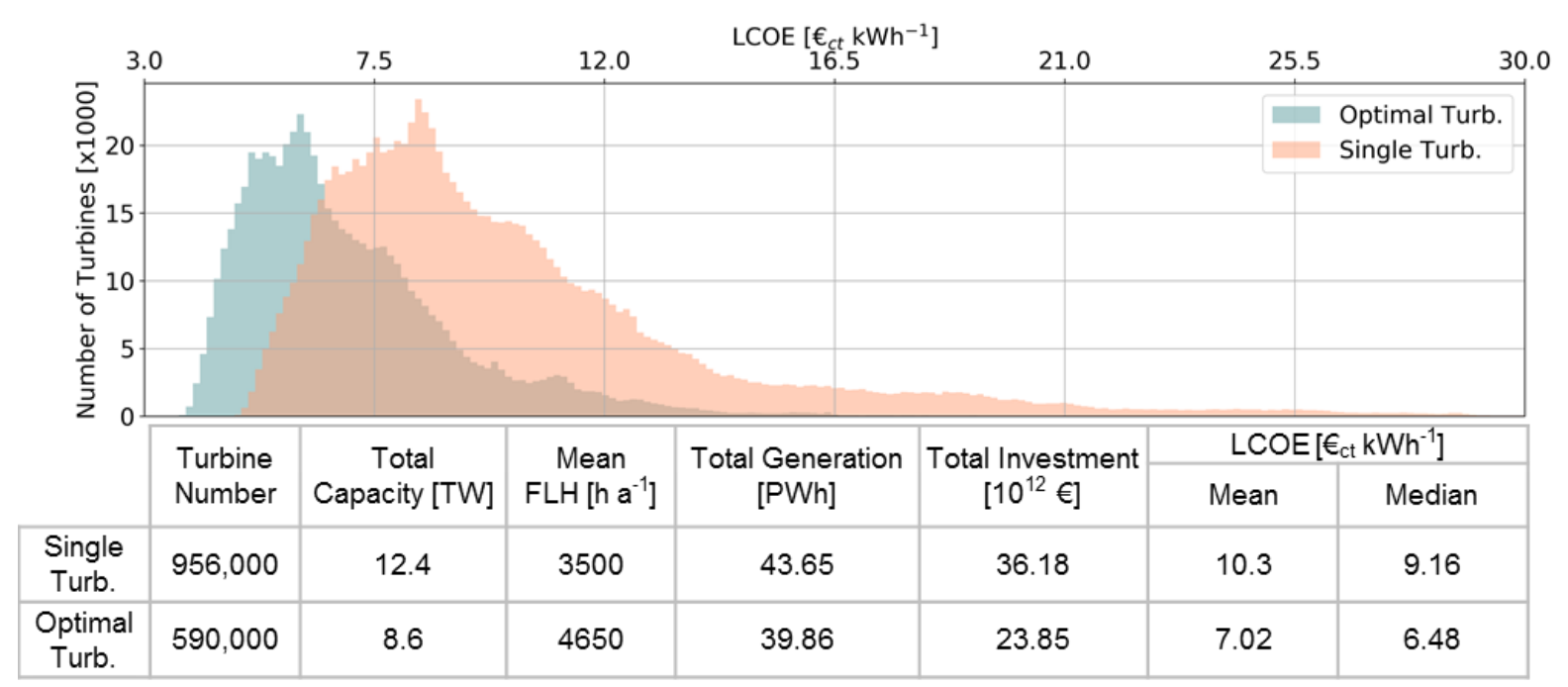

Figure 5. Comparison of single turbine and cost-optimal turbine design analyses.

The distribution of specific investment is shown in Figure 6(a). A strong correlation between specific investment and distance to shore can be seen, especially in the North Sea, where the water depth gradient is gradual. While specific investment is always below $3000 € \mathrm{~kW}^{-1}$, around the nearshore, the cost values in the middle of the North Sea as well as in the Celtic Sea are doubled mainly because of distance to the shore. This puts the original assumption of $2300 € \mathrm{~kW}^{-1}$ into perspective. Although this value is often observed in the results shown here, especially in near-shore areas in the North Sea region, the distribution of the turbine cost depends heavily on the regional context. Hence, this value from literature can be seen as valid for some locations or as an average value across Europe; nevertheless, the real cost varies at each location due to its dependence on water depth, shore distance and other parameters. When Figure 6(b) is examined, the lowest LCOEs are found in the North Sea and around the British Isles, especially close to shore; which is expected due to high wind speeds (resulting in high FLH), low distance to shore and water depth for the turbine cost. In spite of this, there are other regions with equally or slightly less competitive costs, such as the Baltic Sea, Mediterranean Sea near Southern France and within the Bay of Biscay near the Western tips of Spain and France. When specific investment and LCOE values are compared one to one, it can be concluded that the low specific cost of a turbine does not always mean low LCOE. By comparing between costs in the Adriatic Sea versus the far offshore region to the west of the British Isles, this aspect is strongly pronounced. 


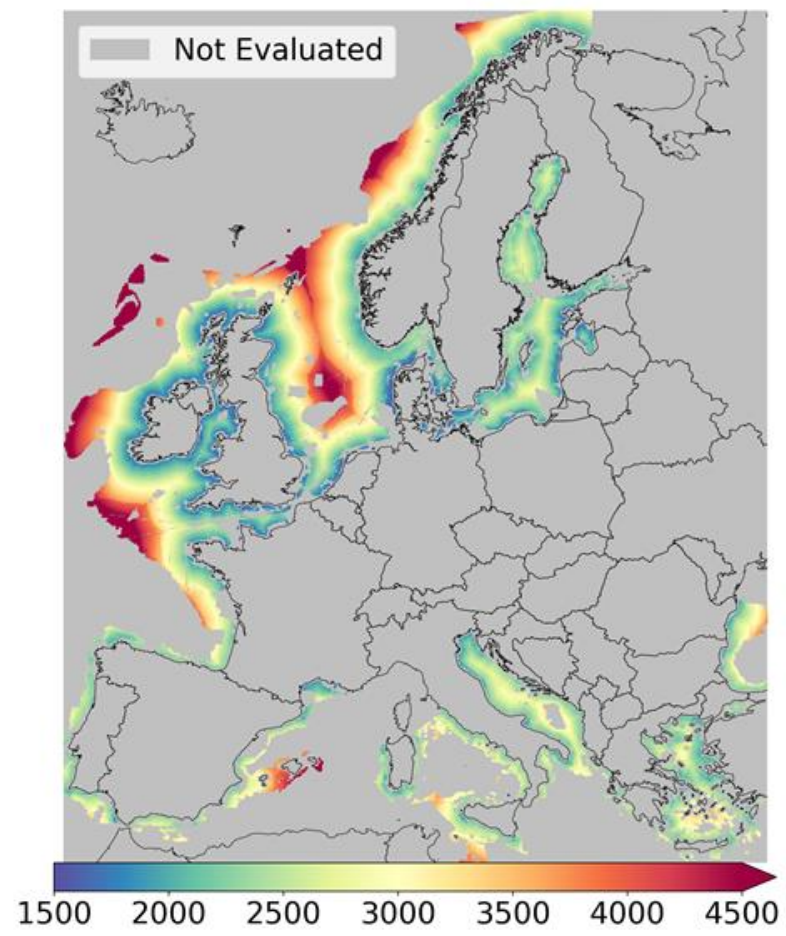

(a) Specific Investment [€ kW-1]

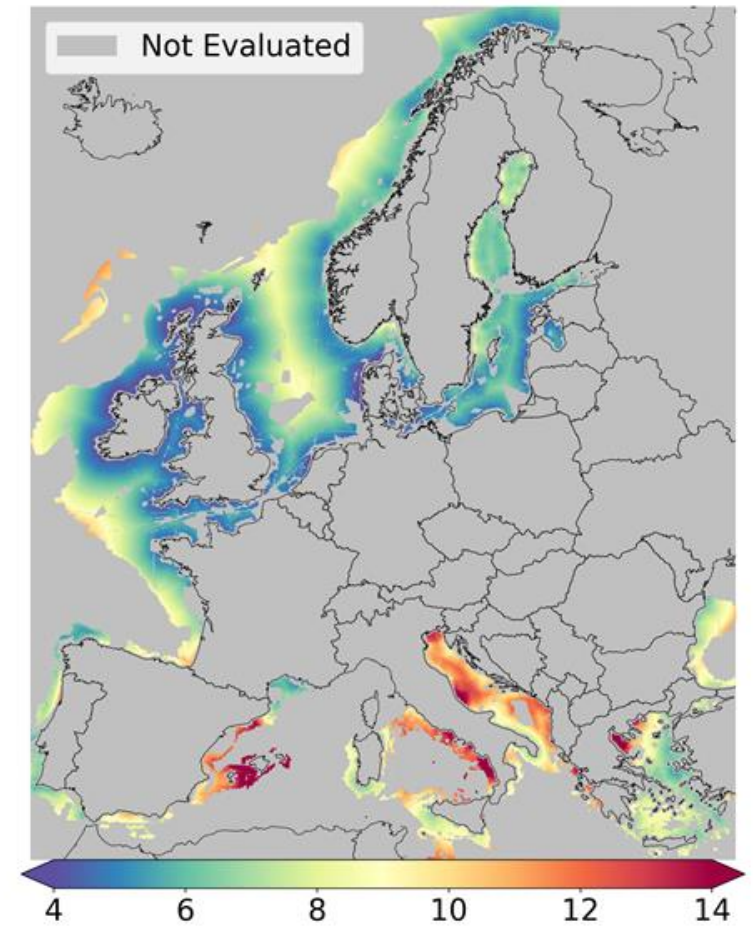

(b) LCOE $\left[\epsilon_{\mathrm{ct}} \mathrm{kWh}^{-1}\right]$

Figure 6. Distribution of (a) specific investment and (b) LCOE across eligible areas.

Figure 7 shows the change in average LCOE with respect to the installed capacity, as well as the total installed capacity of each country when they are sorted by LCOE. Additionally, the markers show the maximum available capacity and corresponding average LCOE. The average LCOE values in this analysis are found to be substantially lower than those presented in Section 3.3 and in the literature. This is due to the fact that most existing studies and the single-turbine scenario results are based on contemporary turbine designs or on a single turbine design applied to all locations. In most countries, there are many locations with LCOEs less than $6 €_{\mathrm{ct}} \mathrm{kWh}^{-1}$, which is also a threshold mentioned by Ryberg et al. [32] in their analysis of onshore wind energy. Detailed capacity potentials at national level with these thresholds are provided in appendix. The share of available capacity below an economic threshold of $6 €_{\mathrm{ct}} \mathrm{kWh}^{-1}$ varies for each country. For instance, Portugal can provide $10 \mathrm{GW}$ of capacity corresponding to $10 \%$ of its overall potential capacity, whereas this value is $50 \mathrm{GW}$ with a share of $25 \%$ for Spain. For countries such as Ireland, Germany and Denmark, the average LCOE is always below the threshold of $6 €_{\mathrm{ct}} \mathrm{kWh}^{-1}$, even at the maximum available capacity. On the other hand, there are some countries that are well above this threshold. Italy, Croatia, Montenegro and Albania perfectly exemplify this, as most of their available locations are designed with floating foundations due to high water depth causing an increase in the specific investment, coupled to a relatively low FLH in the Adriatic Sea. In total, 3.3 TW of capacity and 16.2 PWh of total generation potential are below $6 €_{\mathrm{ct}} \mathrm{kWh}^{-1}$. 

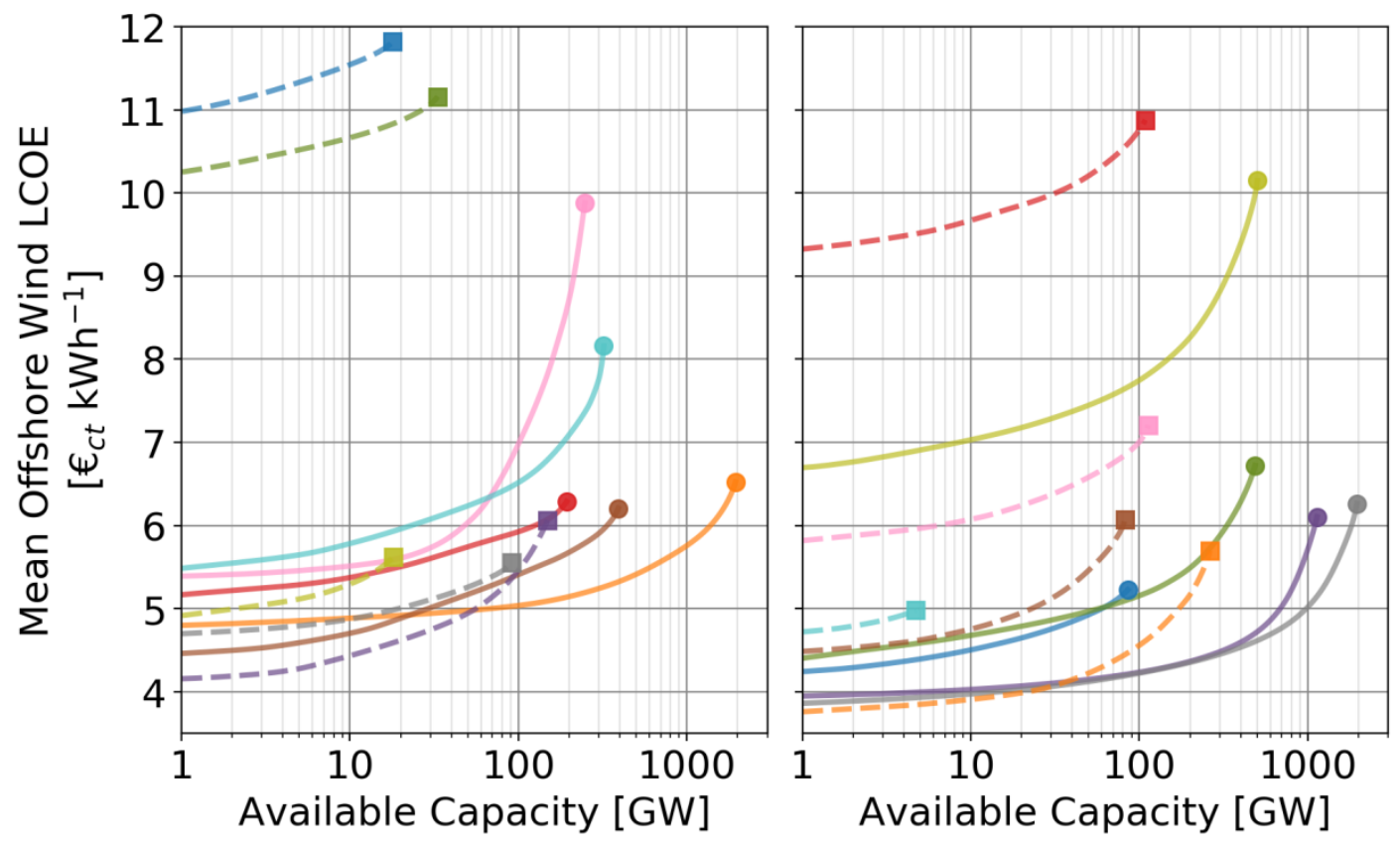

$\begin{array}{llll}\longrightarrow \text { Norway } & -\oplus \text { Albania } & \longrightarrow \text { Estonia } & -=\text { Denmark } \\ \longrightarrow \text { Spain } & -- \text { Netherlands } & \longrightarrow \text { France } & -=\text { Portugal } \\ \longrightarrow \text { Sweden } & -- \text { Poland } & \longrightarrow \text { Ireland } & -=\text { Germany } \\ \longrightarrow \text { Finland } & -- \text { Lithuania } & \longrightarrow \text { U.K. } & -=\text { Croatia } \\ \longrightarrow \text { Greece } & -- \text { Montenegro } & \longrightarrow \text { Italy } & -=\text { Belgium }\end{array}$

Figure 7. Variation of average LCOE as a function of total available capacity at the national level.

\section{CONCLUSION}

A techno-economic offshore wind energy analysis across Europe that takes sociotechnical constraints into account and the three fundamental issues that form the method of this analysis is outlined in this manuscript. An ocean eligibility analysis applied uniformly on European maritime boundaries with a set of constraints reveals that $31.5 \%$ of the areas within the region of interest are available. Independent of ocean eligibility, as a result of the proposed turbine design at each location on a $5 \mathrm{~km}$ grid, it is not economically viable to install the same turbine design everywhere across a large region. As expected, turbines with smaller specific power are selected for locations that have relatively low wind speeds. On the other hand, high hub heights are not always preferred in these locations, unlike expected trends in onshore wind turbine design. Increase in the turbine cost due to higher hub height is more dominant compared to the increase in the FLH. When the simulation and eligibility results are combined in an analysis with a single turbine definition (with a capacity, rotor diameter and hub height of $13 \mathrm{MW}, 212 \mathrm{~m}$ and $128 \mathrm{~m}$, respective), the total available capacity across Europe is found to be $12.4 \mathrm{TW}$, with an average FLH of $3500 \mathrm{~h} \mathrm{a}^{-1}$ and 
generation potential of 43.65 PWh; whereas these results with location-specific turbine designs are 8.6 TW, $4650 \mathrm{~h} \mathrm{a}^{-1}$ and $39.86 \mathrm{PWh}$. It is shown that the use of a single turbine definition in a large region such as Europe significantly affects the capacity factor. Finally, variation in the average LCOE with respect to the available capacity is analyzed by aggregated locations previously sorted by LCOE. It is noteworthy that $38 \%$ of the locations have an LCOE below $6 €_{\mathrm{ct}} \mathrm{kWh}^{-1}$, which makes offshore wind energy comparable to other renewable energy sources such as onshore wind energy. The European capacity and generation values below this threshold are $3.3 \mathrm{TW}$ and 16.2 PWh, respectively.

The results presented in this work are naturally dependent on the assumptions and scenarios. Nevertheless, these results can be used in future energy system designs, as well as decision making processes about offshore wind farm location and design. In order to improve the results, the impact of the assumptions on the results should be investigated in further analyses. For instance, ocean eligibility constraints due to changing socio-political frameworks can be changed or the baseline turbine cost and its definition can be derived differently.

\section{ACKNOWLEDGMENTS}

This work was supported by the Helmholtz Association under the Joint Initiative "EnergySystem 2050: A Contribution of the Research Field Energy".

\section{REFERENCES}

[1] IRENA. Renewable capacity statistics 2018. Abu Dhabi: 2018.

[2] European Commission. EU Reference Scenario 2016 - Energy, transport and GHG emissions - Trends to 2050. 2016. doi:10.2833/001137.

[3] Sanchis G. Europe's future secure and sustainable electricity infrastructure: eHighway2050 project results. 2015.

[4] IRENA. The Power to Change: Solar and Wind Cost Reduction Potential to 2025. 2016.

[5] Greenpeace. Energy [ R ] Evolution - A sustainable World Energy Outlook 2015. 2015. doi:Energ [R]evolution Greenpeace.

[6] Hundleby G, Freeman K. Unleashing Europe's offshore wind potential- A new resource assessment. 2017.

[7] European Environmental Agency. Europe's Onshore and Offshore Wind Energy Potential: An Assessment of Environmental and Economic Constraints. Copenhagen: 2009. doi:10.2800/11373.

[8] Arent D, Sullivan P, Heimiller DM, Lopez A, Eurek K, Badger J, et al. Improved Offshore Wind Resource Assessment in Global Climate Stabilization Scenarios. Golden: 2012.

[9] Bosch J, Staffell I, Hawkes AD. Temporally explicit and spatially resolved global offshore wind energy potentials. Energy 2018;163:766-81. doi:10.1016/j.energy.2018.08.153. 
[10] Zappa W, van den Broek M. Analysing the potential of integrating wind and solar power in Europe using spatial optimisation under various scenarios. Renew Sustain Energy Rev 2018;94:1192-216. doi:10.1016/j.rser.2018.05.071.

[11] Staffell I, Pfenninger S. Using bias-corrected reanalysis to simulate current and future wind power output. Energy 2016;114:1224-39. doi:10.1016/J.ENERGY.2016.08.068.

[12] Heinrichs HU, Jochem P. Long-term impacts of battery electric vehicles on the German electricity system. Eur Phys J Spec Top 2016;225:583-93. doi:10.1140/epjst/e201550115-x.

[13] European Commission. The JRC-EU-TIMES model - Assessing the long-term role of the SET Plan Energy technologies. 2013. doi:10.2790/97596.

[14] Dhakouani A, Gardumi F, Znouda E, Bouden C, Howells M. Long-term optimisation model of the Tunisian power system. Energy 2017;141:550-62.

doi:10.1016/j.energy.2017.09.093.

[15] Syranidis K, Robinius M, Stolten D. Control techniques and the modeling of electrical power flow across transmission networks. Renew Sustain Energy Rev 2018;82:3452-67. doi:10.1016/j.rser.2017.10.110.

[16] IRENA. Renewable Power Generation Costs in 2017. Springer-Verlag; 2018.

[17] Pfenninger S, Hirth L, Schlecht I, Schmid E, Wiese F, Brown T, et al. Opening the black box of energy modelling: Strategies and lessons learned. Energy Strateg Rev 2018;19:6371. doi:10.1016/j.esr.2017.12.002.

[18] Ryberg DS, Tulemat Z, Robinius M, Stolten D. Geospatial Land Availability for Energy Systems (GLAES) 2017. http//github.com/FZJ-IEK3-VSA/glaes.

[19] Robinius M, Otto A, Heuser P, Welder L, Syranidis K, Ryberg D, et al. Linking the Power and Transport Sectors_-Part 1: The Principle of Sector Coupling. Energies 2017;10:956. doi:10.3390/en10070956.

[20] Robinius M, Otto A, Syranidis K, Ryberg DS, Heuser P, Welder L, et al. Linking the Power and Transport Sectors-Part 2: Modelling a Sector Coupling Scenario for Germany. Energies 2017;10:957. doi:10.3390/en10070957.

[21] Hong L, Möller B. Offshore wind energy potential in China: Under technical, spatial and economic constraints. Energy 2011;36:4482-91. doi:10.1016/j.energy.2011.03.071.

[22] Jay S. Planners to the rescue: Spatial planning facilitating the development of offshore wind energy. Mar Pollut Bull 2010;60:493-9. doi:10.1016/j.marpolbul.2009.11.010.

[23] The GEBCO_2014 Grid, version 20141103 n.d. http://www.gebco.net.

[24] Global Administrative Areas. GADM database of Global Administrative Areas, version 2.02012 .

[25] UNEP-WCMC and IUCN. Cambridge U. Protected Planet: The World Database on Protected Areas (WDPA)[On-Line] 2016.

[26] Halpern B, Frazier M, Potapenko J, Casey K, Koenig K, Longo C, et al. Cumulative human impacts: raw stressor data (2008 and 2013). Knb 2015. doi:10.5063/F1S180FS. 
[27] WorldMap. Natural Gas Pipelines in Europe, Asia, Africa \& Middle East n.d. https://worldmap.harvard.edu/data/geonode:natural_gas_pipelines_j96 (accessed April 4, 2017).

[28] EMODnet Human Activities: Telecom cables (schematic routes) 2014.

[29] EMODnet Human Activities, Cables, Actual Routes 2015.

[30] James R, Ros MC. Floating Offshore Wind: Market and Technology Review Important notice and disclaimer. 2015. doi:1472-6807-11-4 [pii] r10.1186/1472-6807-11-4 [doi].

[31] Hill M, Briggs J, Minto P, Bagnall D, Foley K, Williams A, et al. Guide to Best Practice in Seascape Assessment Countryside Council for Wales. Marit INTERREG Ser 2001.

[32] Ryberg DS, Caglayan DG, Schmitt S, Linßen J, Stolten D, Robinius M. The Future of European Onshore Wind Energy Potential : Detailed Distribution and Simulation of Advanced Turbine Designs. Preprints 2018. doi:10.20944/preprints201812.0196.v1.

[33] Drennan WM, Taylor PK, Yelland MJ. Parameterizing the Sea Surface Roughness. J Phys Oceanogr 2005;35:835-48. doi:10.1175/JPO2704.1.

[34] Ejsing Jørgensen, Hans; Nielsen, Morten; Barthelmie, Rebecca Jane; Mortensen NG. Modelling offshore wind resources and wind conditions 2005.

[35] Stehly TJ, Heimiller DM, Scott GN. 2016 Cost of Wind Energy Review. 2017.

[36] Fingersh LJ, Hand MM, Laxson AS. Wind turbine design cost and scaling model. Golden: 2006.

[37] Maples B, Hand M, Musial W. Comparative assessment of direct drive high temperature superconducting generators in multi-megawatt class wind turbines. Golden: 2010.

[38] Maness M, Maples B, Smith A. NREL Offshore Balance-of System Model. Golden: 2017.

[39] Roadmap 2050: A Practical Guide to a Prosperous, Low-carbon Europe. 2010.

[40] Wiser R, Jenni K, Seel J, Baker E, Hand M, Lantz E, et al. Expert elicitation survey on future wind energy costs. Nat Energy 2016;1:16135. doi:10.1038/nenergy.2016.135.

[41] Amaral L, Castro R. Offshore wind farm layout optimization regarding wake effects and electrical losses. Eng Appl Artif Intell 2017;60:26-34.

doi:10.1016/j.engappai.2017.01.010.

[42] J. Carlsson, M. del Mar Perez Fortes, G. de Marco, J. Giuntoli, M. Jakubcionis, A. JägerWaldau, R. Lacal-Arantegui S, Lazarou, D. Magagna, C. Moles, B. Sigfusson, A. Spisto, M. Vallei, EW. ETRI 2014 - Energy Technology Reference Indicator projections for 2010-2050. 2014. doi:10.2790/057687.

[43] Nielsen P. Vindmollers Okonomi. 2010.

[44] Luderer G, Pietzcker RC, Carrara S, de Boer HS, Fujimori S, Johnson N, et al. Assessment of wind and solar power in global low-carbon energy scenarios: An introduction. Energy Econ 2017;64:542-51. doi:10.1016/j.eneco.2017.03.027.

[45] Kost C, Shammugam S, Jülch V, Nguyen H-T, Schlegl T. Levelized Cost of Electricity Renewable Energy Technologies. 2018. 
[46] Hobohm J, Krampe L, Peter F, Gerken A, Heinrich P, Richter M. Kostensenkungspotenziale der Offshore-Windenergie in Deutschland - Kurzfassung. Berlin: 2013.

[47] Hernández CV, Telsnig T, Anahí Villalba Pradas. JRC Wind Energy Status Report 2016 Edition. Luxemburg: 2017. doi:10.2760/332535.

[48] EWEA. Offshore wind in Europe: Walking the tightrope to success. 2015. 